\title{
El diseño geográfico de la nación en una novela mexicana del siglo XIX. Los bandidos de Río Frío de Manuel Payno
}

\author{
The geographical design of the nation in a nineteenth- \\ century mexican novel. Los bandidos de Río Frío by \\ Manuel Payno
}

\author{
Raquel Urroz Kanán [i]
}

\begin{abstract}
RESUMEN
Los bandidos de Río Frío, de Manuel Payno,es una novela nacionalista situada en las primeras décadas del México independiente, cuando se busca la idea de nación por medio de la descripción y la construcción cultural del paisaje y del territorio nacional. Se explora una "literatura geográfica" a través del enfoque que proviene de la geografía cultural. Seguimos en ello a Tuan, quien conceptualiza los lugares simbólicos con cualidades sociales como epicentros que personifican la vida cultural y la identidad de cierta comunidad. A partir de este enfoque, ¿cómo se expone la percepción espacial del autor con respecto al territorio nacional? Para ello, se analizan tres ámbitos de la territorialidad tejida en la novela y que son: las haciendas, las montañas y los caminos, los cuales conforman el diseño estructural que concibió Payno para buscar descifrar el sistema espacial que se entretejía a escala nacional.
\end{abstract}

Palabras clave: geografía cultural, paisaje, México, Payno, Yi Fu Tuan.

\begin{abstract}
Los bandidos de Río Frío, by Manuel Payno, is a nationalist novel located in the first decades of independent Mexico, when the idea of nation is sought through the description and cultural construction of the landscape and the national territory. A "geographical literature" is explored through the approach that comes from cultural geography. We follow Tuan, who conceptualizes symbolic places with social qualities, as epicenters that personify cultural life and the identity of a certain community. From this approach ihow is the author's spatial perception exposed with respect to the national territory? For this, we analyze three areas of territoriality woven in the novel and that are: the haciendas, the mountains and the roads, which make up the structural design that Payno conceived to seek decipher the spatial system that was interwoven on a national scale
\end{abstract}

Keywords: cultural geography, landscape, México, Payno, Yi Fu Tuan

Instituto de Geografía, Universidad Nacional Autónoma de México, Ciudad de México. Departamento de Geografía Social, Instituto de Geografía, UNAM. raquelurroz@gmail.com 


\section{RESUMO}

Los bandidos de RíoFrío, de Manuel Payno, é um romance nacionalista ambientado nas primeiras décadas do México independente, quando a ideia de nação é buscada através da descrição e construção cultural da paisagem e do território nacional. Uma "literatura geográfica" é explorada através da abordagem que vem da geografia cultural. Nisto acompanhamos Tuan, que conceitua lugares simbólicos com qualidades sociais como epicentros que personificam a vida cultural e a identidade de uma determinada comunidade. A partir dessa abordagem, como se expõe a percepção espacial do autor em relação ao território nacional? Para tanto, são analisadas três áreas de territorialidade tecidas no romance e são elas: haciendas, montanhas e estradas, que compõem o desenho estrutural que Payno concebeu para buscar decifrar o sistema espacial que se entrelaçou em escala nacional.

Palavras-chave: geografia cultural, paisagem, Mexico, Payno, Yi Fu Tuan.

La más amplia novela del siglo XIX mexicano, así como una de las fundadoras de la literaturanacionalistaes, sin duda,Los bandidos de Río Frío. Entre 1889 y 1891 su autor, Manuel Payno, narró y representó el siglo que él mismo atravesó en sus primeras décadas de país independiente. ${ }^{2}$ Los bandidos, aunque es ficción, resulta en una suerte de tratado socio-histórico escrito de forma no lineal, sino con las características del llamado folletín (Monsiváis, 1997; Blanco, 2015), el cual, no obstante, plasma los sistemas culturales que se tejían desde el poder,así como desde la vida cotidiana en su carácter popular(Ruiz, 2007; Glantz, 2010). Los bandidos no es sólo un gran cuadro de costumbres y de tipos sociales, sino que constituye un panorama cultural del paisaje y del territorio nacional que está en vías de gestación a partir de su Independencia y en tiempos santanistas. ${ }^{3}$

Ahora bien, dentro de este marco literario y en la narrativa de Payno,los espacios nacionales se hallan en proceso de reordenamiento -a lo largo de un periodo de transición y antes del triunfo del liberalismo. De hecho, en el siglo XIX, comenzaba a cultivarse una tradición que hoy podríamos definir como "literatura geográfica", dedicada (de manera consciente o no) a describir las narrativas espaciales. En México, Quirarte la ha denominado "geografía literaria" y se trata de la dimensión espacial en la ficción que permite tejer las historias dentro de un marco de acción continuo (2016: 28-29).

Para analizar esta "geografía literaria" a escala nacional, dentrode Los bandidos, se propone el enfoque que proviene de la geografía cultural, el cual privilegia las representaciones espaciales donde el paisaje es entendido como "el lenguaje de las formas", y, que, "reunidas, constituyen lo que alguna vez fue aquel ambiente" (Fernández, 2017:56). Dentro de esta misma perspectiva, pero en el caso concreto de la narrativa literaria, seguimos a Yi Fu Tuan. El geógrafo de origen chino explica cómo es que los lugares en la novela no son simples localizaciones, sino que están imbuidos de sentido, de personalidad, en fin, de espíritu (2018: 58). Tuan lo explica como una posición social que permite imbuir y saturar el espacio vivido de ciertos rasgos a partir de un contacto largo, prolongado y repetido (2018: 86). Esto es: sin importar la escala, se construyen "epicentros" que, a decir de Tuan, logran personificar la vida cultural y la identidad de cierta comunidad. Ahora bien, para que estos espacios dejen de ser abstractos y se llenen de vida, el escritor necesita conferir-

\footnotetext{
La más completa biografía de Payno es de Robert Duclas (1979), mientras que sus obras completas —coordinadas por Boris Rosen Jélomerfueron compiladas entre 1996 y 2013, en 17 tomos y publicadas por el Consejo Nacional para la Cultura y las Artes de México.

3 San Anna fue un caudillo, militar, y presidente de México en seis ocasiones entre los años 1833 y 1855.
} 
lesuna cualidad metafísica que permita visibilizar o crear una realidad que alcance la conciencia pública hasta quedar arraigada. ${ }^{4}$

En este trabajo, se expone, por un lado, la postura ypercepción espacial del autor con respecto al territorio nacional y sus fronteras, las cuales, se tambaleaban y veían amenazadas a raíz de la guerra de Independencia. Por el otro,el texto analiza tres ámbitos de la territorialidad tejida en la novela, donde los personajes brindan "personalidad" e "identidad" a los lugares modelados con sus acciones y sus relaciones las cuales, permitieron anudar vínculos entre ellos. Las haciendas, las montañas y los caminos, fueron sitios considerados fundamentales por Payno dado que representaban epicentrosindispensables para la construcción de la idea de nación en la conciencia pública de la nueva ciudadanía mexicana.

\section{El territorio nacional y el nacionalismo en Payno}

Si pensamos en el nacionalismo como un proceso, una ideología, un proyecto, pero también como una condición geográfica de naturaleza histórica y moral, se puede seguir a Anderson (1991) cuando afirma que imaginar y pensar el territorio es conceptualizar el espacio delimitado. ${ }^{5}$ En efecto, para las primeras décadas del México independiente, el modelo espacial de alcances nacionales, se esbozaba precariamente desde el Estado y únicamente por medio de la difusión de mapas, imágenes, símbolos y creaciones artísticas (Carrera, 2011; Soriano, 2018). En cambio, las publicaciones de relatos, novelas, crónicas y cuadros de costumbres, fueron herramientas intelectuales poderosas que permitieron difundir una narrativa espacial o, como lo expresa Schlögel, "espacios mentales" como imágenes de sí mismos(2007: 201).

Es el caso de Manuel Payno, junto con sus experiencias y percepciones recogidas a lo largo de sus viajes y publicadas ennumerosos artículos y notas periodísticas que describían los paisajes nacionales y sus ideas al respecto. Destacan los itinerarios que trazó, desde muy joven, por los departamentos del norte, dado que, a raíz de ellos, nacía una de sus obsesiones: la configuración de las fronteras como elemento indispensable para salvaguardar el espacio nacional. ${ }^{6}$ No obstante, a mediados del siglo, el septentrión mexicano o las denominadas "provincias internas", eran una

\footnotetext{
Yi Fu Tuan explica que las relaciones humanas requieren objetos materiales para consolidarse, y ésta experiencia acaece en localidades concretas, es decir, en espacios que se vuelven "íntimos" o se convierten en "áreas de cuidado", donde se expresan experiencias repetidas (2018: 95). Sobre el nacionalismo y el problema de la identidad en el México independiente, véase: Annino, 2010 y Guerra, 2014.

6 Payno, al igual que los escritores de su generación, estaba obsesionado por la prosperidad del área norte del país, junto con la defensa de sus fronteras. De ello dependía la supremacía del Estado, la cual se encontraba desvalida frente al expansionismo y la colonización de Norteamérica. Aunque en las regiones del sur del territorio nacional acaecían enfrentamientos entre facciones políticas y se desarrollaban fuertes movimientos separatistas, éstos no eran tomados demasiado en cuenta por los intelectuales para el propósito de conformar un proyecto de unidad nacional. En cambio, era el lejano, poco poblado y amenazado septentrión mexicano, la verdadera preocupación y apuesta, ya que, gracias a sus oligarquías ricas, la nación podía ser integrada económicamente y; desde la capital, controlada políticamente. El naciente reacomodo jurídico-territorial a partir de la Independencia debía ser, por tanto, un proceso que articulara, en un solo sistema espacial, el mapa nacional a partir de las relaciones entre el centro y las regiones del norte del país.
} 
división político-militar,percibidas como proyecto de estado para la defensa contra invasiones ${ }^{7}$ y, al mismo tiempo,empresa para la colonización. ${ }^{8}$

Pero antes de pensar en la protección de las fronteras, su principal preocupaciónera, más bien, la posible desintegración del territorio nacional. Payno comprendía bien que la unión de todas las provincias bajo un solo gobierno federal estaba en juego frente a las aspiraciones separatistas de Texas, Durango, Tamaulipas, Zacatecas y Guadalajara (Figura № 1). Todas ellas,representaban "la tradición levantísca del pueblo", ${ }^{9}$ donde se buscaba no sólo contrarrestar, sino impedir la prevalencia de la capital (García, 2014b: 380). También, eran provincias que pretendían continuar con los privilegios colonialesy, a decir de Payno, el "ruido local" en los estados de Jalisco, Querétaro, Zacatecas, San Luis Potosí, Coahuila y Yucatán, provenía de las "rebeliones entre gobernadores y legislaturas de estados" (2006: 222)(FiguraN¹). Sobre todo, era el estado de "Jalisco que ha estado en un perpetuo disgusto con el gobierno federal a causa de la separación de Tepic, y además ha sido materialmente presa de bandidos y plagiarios" (2006: 251). En Los bandidos, en efecto, es Jalisco, junto con su capital que es Guadalajara, donde "se levantó la revolución", y a donde escapan la gran mayoría de "macutenos o rateros" (Payno, 2016: 609). ${ }^{10}$

\footnotetext{
Desde Durango y Chihuahua, y hasta el paso del norte, la tierra se encontraba muy despoblada, fuera de las "colonias militares", las cuales fungían como zonas adelantadas. Estas compañías presidiales de caballería, hacían regularmente sus correrías en los departamentos de oriente -Tamaulipas, Nuevo León, Coahuila, Chihuahua, Durango, Nuevo México, Sonora y Sinaloa-, con el fin de repeler incursiones "bárbaras", quienes bajaban del desierto de "Tejas", Nuevo México y las Californias (Payno, 1999: 52-53) (Figura N¹). Esta situación, precisamente, Payno la exploró a lo largo de sus viajes por el norte, y denunció el estado en que se encontraba el cinturón de presidios fronterizos, sobre todo, para advertir que estaban compuestos de poca tropa y, por tanto, en el permanente desamparo (1999: 32)

8 Hacia 1842, Payno escribía sobre el fomento a la colonización y declaraba: "Nuestros enemigos velan, y nosotros dormimos; ellos conocen que el río Bravo es un tesoro, y nosotros lo desperdiciamos: la población del otro lado del Bravo es activa, audaz y emprendedora; la de esta parte es indolente y descuidada. El norte es un torrente que amenaza sorber nuestras posesiones. Es menester un dique. Este dique es el aumento de la población" (1999: 41). Para 1844, Payno insistía: "la frontera trazada por la naturaleza debe ser el río Bravo; la frontera que trace la política del gobierno debe ser Matamoros, así pues, debe formarse allí esa línea que divida la raza invasora de la propietaria y poner un dique para evitar ese cáncer lento, pero seguro" (1999: 111).

9 Esta era una de las tres razones, creía Payno, por las que no avanzaba la nación hacia el progreso, las otras dos eran: "el espíritu de hacer partidos" y "el escaso respeto a las leyes" (2002: 34).

10 En la novela, los soldados federales —encabezados por el general de Brigada Baninelli- están obligados a proteger Jalisco, Zacatecas y Durango (Payno, 2016: 985-986). Esto, después de que los bandoleros - sobre todo, Valentín Cruz- tomaron el Ayuntamiento de Guadalajara, una vez habiendo asaltado las haciendas para obtener armas y caballos (Payno, 2016: 985).
} 
Figura $\mathrm{N}^{\circ} 1$

El Norte de México y las fronteras narradas por Payno

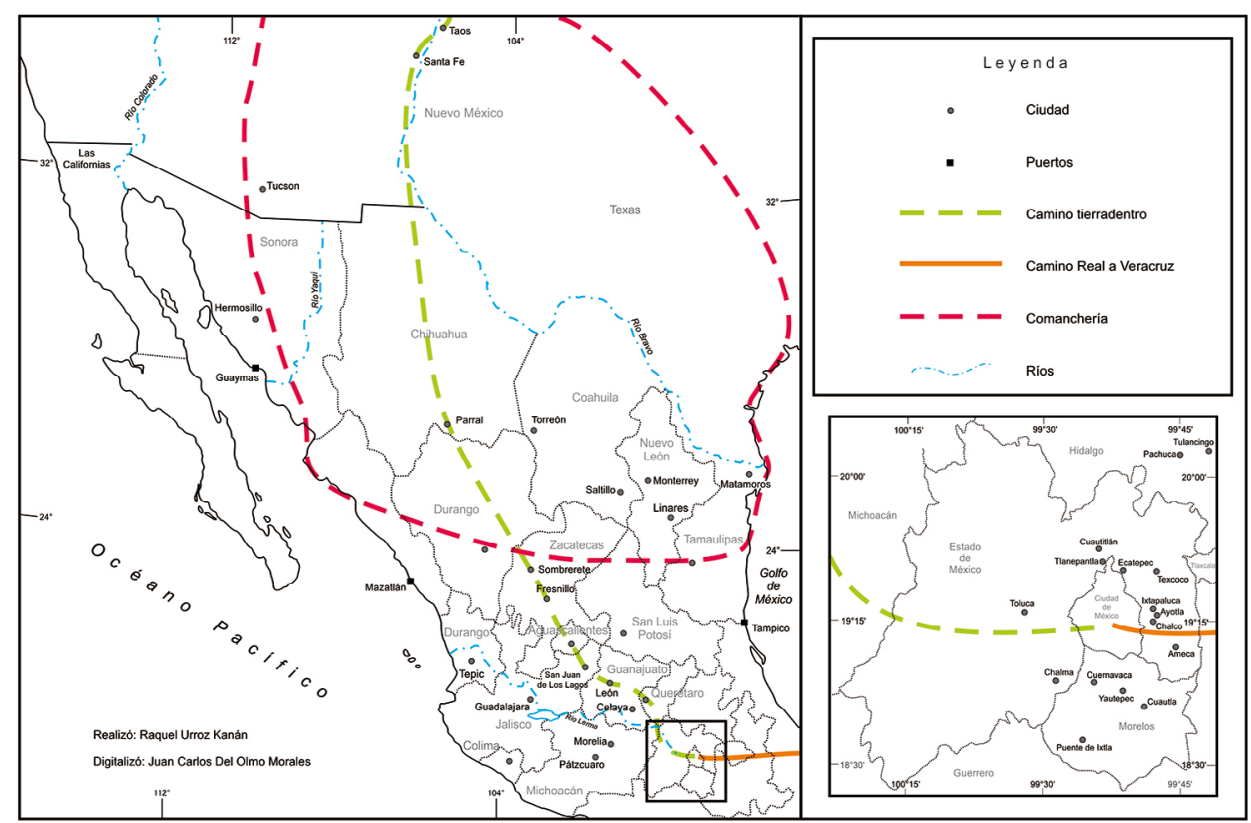

Fuente: Elaboración propia

El otro gran interés que tenía Payno - para ser plasmado en la novela - con respecto a la construcción del territorio nacional, no era una posible invasión estadounidense -lo que sucedería en las décadas posteriores-, sino que eran“las numerosas tribus que han repetido sus incursiones sobre las poblaciones", dejando contantemente "escenas de sangre y de horror". Los comanches, precisamente,eran la "nación más numerosa y guerrera", conformada por tribus del desierto que acostumbraban robar caballos y mujeres. Explica Payno que, desde el Bravo y hasta el Colorado, habitaban "los más dados a la guerra", que eran los mismos "aficionados al robo" (Payno, 1999: 33). Payno hace un esfuerzo por comprender las costumbres de aquellos poderosos jinetes y cazadores que cruzaban el río en forma de bandas y en expediciones de saqueo a territorio mexicano. Sin embargo, enLos bandidosno se enfatiza sus necesidadesde intercambio comercial, por ejemplo, sino su deseo por el botín: plata y caballos, pero tambiénprestigio y venganza celebrando con ello el éxito de sus expediciones. ${ }^{11}$ En suma, a Payno le interesa saber más sobre estos bravos indios, pero sólo en la medida en queasaltaban haciendas y ranchos localizados a lo largo de la franja que corre desde Torreón, pasando por Coahuila, Durango, Chihuahua y hasta descender, incluso, al departamento de Zacatecas (Figura $\mathrm{N}^{\circ} 1$ ). Combatir este mal y reforzar los presidios en la frontera, era la fórmula, pues, de proteger ranchos y haciendas, las cuales, a su vez, pudieran formar villas y, éstas, eventualmente, adquirieran el rango de ciudades (Payno, 1999: 52).

Es el capítulo LIX de Los bandidos, donde se narra con detalle la forma en que "los salvajes" irrumpen y atacan con flechas y rifles la hacienda del Sauz, incluso, hasta someter a Don Manuel y celebrar la victoria sobre él humillándolo. 


\section{Tres ámbitos de territorialidad mexicana en Los bandidos}

A continuación, se han elegido tres espacios dentro de la novela que, en palabras de Yi Fu Tuan, se volvieron"símbolos públicos", los cuales, más allá de su estructura formal o su apariencia física, representan"centro vital de significado" (2018: 88). Por su parte, la idea de territorialidad hace referencia a estos elementos espaciales que,en conjunto,representan la integración -para bien o para mal- de la idea y del concepto de nación que se está desarrollando en la primera mitad del siglo XIX. De modo que, teniendo el diseño que concibió Payno en las páginas de Los bandidos, es posible comenzar a descifrarel sistema espacial que se entrelaza, con el fin de tener la composiciónde la nacionalidad mexicana que se proyectabasobre el territorio mexicano. ${ }^{12}$

\section{Las haciendas}

Para la primera mitad del siglo XIX, México era predominantemente una sociedad rural..$^{13}$ Esto es, el paisaje nacional estaba dominado por los pueblos agrícolas y sus parcelas que se entreveraban y se veían absorbidos por la figura espacial que representaban las haciendas de labor o ganaderas; pero también por las unidades menores o ranchos, los cuales comenzaban a multiplicarse frente a los grandes latifundios (Brading, 1995: 19)..$^{14}$

En una digresión de la novela, Payno refiere que: "En los pueblos y ciudades de segundo orden de México, los dueños de las haciendas son los potentados, los señores, y forman el núcleo de la aristocracia de provincia". El cura, los alcaldes, los ayuntamientos, todo el mundo les hace "randi bus", como dicen los rancheros" (2016: 395). Es un hecho, pues,que el poder de toda clase nueva - o gatoparda- se medía por la posesión de la tierra: los propietarios de haciendas eran los ricos, los menos ricos tenían ranchos, y los verdaderamente influyentes tenían haciendas, más casas y fincas de campo (2016: 1105).

Los mineros, los comerciantes $y$, en menor medida, los religiosos, ${ }^{15}$ administrabanestas unidades de producción privada (Nickel, 1988: 143). ${ }^{16}$ Sus funciones se desligaban paulatinamente y se independizaban cada vez más de las jurisdicciones de cualquier poblado o corporación original. Esta fue la manera efectiva de sobrevivir frente a los cambios que provocó la insurgencia, es decir,su permanencia dependía, ya, únicamente de llevar una buena administración. En Los

\footnotetext{
Los bandidos registra una gran cantidad de lugares, paisajes y trayectos comunes que adquieren diversos significados culturales. Otra forma de analizar y descomponer el territorio nacional a través de las prácticas espaciales de los personajes en la novela, es articular una geografía cultural que parta de la propia capital del país. En un trabajo anterior, se ha propuesto dar lectura al paisaje urbano dela ciudad de México junto con la zona centro para descifrar un sistema espacial a nivel nacional e interregional. En otras palabras, es a partir de la capital, como epicentro desde el cual se proyecta el resto del territorio nacional y, por tanto, el diseño geográfico de la nación en Payno (Urroz, 2019).

13 En teoría, la tierra se organizaba y estructuraba en cuatro tipos: fundo legal, tierras de común repartimiento, ejidos y montes y bosques, pero en la práctica, se sufrian nuevas transformaciones espaciales que afectaban a las corporaciones eclesiásticas y a los pueblos de indios (Escobar, et al, 2017: 16)

14 En Los bandidos, se describe el entorno de la hacienda propiedad de don Manuel, conde de San Diego del Sauz, donde están los ranchos y aldeas distribuidas alrededor (Payno, 2016: 1185-1186).

15 Un ejemplo en la novela, es la finca y capilla de los jesuitas, ubicada en San Martín, la cual, se convirtió en hacienda de trigo y maguey (Payno, 2016: 1153) (Figura N²).

16 Siguiendo a Nickel, se define a la hacienda como un núcleo de población permanente y concentrada; pero también, como empresa de propiedad privada que aspira ser sistema autosuficiente y de autoconsumo. En suma, la hacienda de estos tiempos, representaba la gran institución social y económica que acaparaba la fuerza de trabajo, dominaba los recursos naturales, y formaba parte de circuitos comerciales interregionales (1988: 19)
} 
Bandidos, es el viejo Don Remigio quien administra la ya en decadencia Hacienda de Don Manuel, ubicada en San Diego, cerca de Durango ${ }^{17}$ (Figura $\mathrm{N}^{\circ} 1$ ). Estas grandes unidades espaciales simbolizaban el poder de las "dinastías" o asociaciones familiares, quienesbuscaban preservar su posición mediante lazos de parentesco y así mantener sus dominios territoriales (Langue, 1999: 249). ${ }^{18}$ Ejemplo, es, cuando don Manuel busca la forma de casar a su hija, la condesita, con el Marqués de Valle Alegre, quien representaba la sobrevivencia del estamento que, en tiempos coloniales, fuera dominante.

Otra forma de mantener las propiedades aseguradas, era viajando a la ciudad de México constantemente $y$, con ello, hacer acto de presencia en la capital y concretar,así,su posición social mediante el ejercicio de sus cargos nobiliarios (Langue, 1999: 281). Por ejemplo, los comportamientos y los intereses sociales del Conde don Diego, le permitían proteger sus inversiones. Se lee, al respecto: "Era también fama que el conde recibía en ciertas épocas, visitas de durangueñas y zacatecanas que, procedentes de las haciendas, venían a la capital a arreglar sus cuentas de arrendamientos y tratar otros asuntos de interés" (Payno, 2016: 69).19

El ejemplo contrario sucedía en el estado de Morelos, particularmente en Cuernavaca y Cuautla, los cuales representaban una importante entrada fiscal por la venta de productos comerciales, tales como el azúcar y el aguardiente de caña producidas en las haciendas locales. Estos lugares fueron distritos predilectos de inversionistas, del gobierno recaudador de impuestos, y también de los comandantes armados. En Los bandidos, es en Yautepec, Cuautla y Puente de Ixtla (Figura $N^{\circ} 1$ ), donde "los gachupines" habían abandonado las haciendas y no se sembraba más la caña ni el moliendo de azúcar. De modo que, el capitán, Pedro Cataño, junto con sus "32 muchachos"(la gavilla de "Los Dorados"), podían irrumpir libremente para asaltar y extorsionar a sus dueños o administradores (Payno, 2016: 1481). Esto, con el fin, no sólo de tomar posesión de la hacienda para adquirir caballos, además, para proteger a los "trabajadores oprimidos de sus administradores y las tiendas", y para "solicitarles dinero a los propietarios cortésmente para la causa" (Payno, 2016: 1426-1427).Así, el capitán y sus soldados, se apropiaban del lugar y eran recibidos "según se acostumbra, a cuerpo de rey", de hecho, "la cocina de esas fincas, sus dispendiosos gastos, el mucho dinero que circula y la amplia hospitalidad que se concede aún a las personas desconocidas, tiene algo de grande y de novedoso"(2016: 1405).

Tanto la hacienda, como los ranchos y fincas, se caracterizaban entre otras cosas, por las relaciones sociales que se creaban al interior de sus espacios. El propietario por antonomasia, era el "hombre de a caballo, los verdaderos rancheros sin igualar en destreza, en gallardía y en fuerza" (Payno, 2016: 1219). En Los bandidos, es el pueblo de Tepetlaoxtoc, ${ }^{20}$ el gran ejemplode un

17 La Hacienda del Conde del Sauz, estaba ligada a negocios de minas que estaban en quiebra, con la única excepción de aquella en el poblado de Sombrerete, Zacatecas (Payno, 2016: 427) (Figura Nº1).

18 En esta época de transición, las grandes extensiones de tierra empezaban a ser embargadas o indemnizadas. De modo que, sólo quedaban pocas fortunas que heredaban latifundios y títulos, y, esto, a pesar de la supresión del mayorazgo (Langue, 1999: 275).

19 Cada unidad territorial, tuvo sus particularidades y su patrón espacial en relación a su extensión, a la producción, a la población, a la fuerza de trabajo, y a su entorno (García, 2014a). En la novela, sin embrago, se subraya el propósito -además de ser unidad económica y administrativa- de su comunicación con los caminos reales y los enlaces con la capital. Los propietarios de las haciendas, tal y como lo era don Manuel, tenían su hogar en la ciudad de México, además de que alli se concentraban sus intereses, tanto económicos, como de carácter social. El conde, por ejemplo, "iba y venía a México" permanentemente: unas veces dejaba a su hija en la hacienda, bajo la estrecha vigilancia de don Remigio; otras, la traía consigo a la capital para ser presentada a toda la nobleza capitalina (Payno, 2016: 335).

20 Municipio del Estado de México, conformado por su cabecera y pueblos. Esta localidad, aún no era elevada a rango de Villa, en los tiempos que corren dentro de la novela. 
espacio rural repleto de haciendas que producían maíz y trigo, y que estaban dispuestas en torno ala plaza, la pulquería y, sobre todo, a la gran feriaanual que congregaba a los rancheros (2016: 572-573) (Figura $\mathrm{N}^{\circ} 2$ ).

Figura $\mathrm{N}^{\circ} 2$

El área de bandidaje en Río Frío narrada por Payno

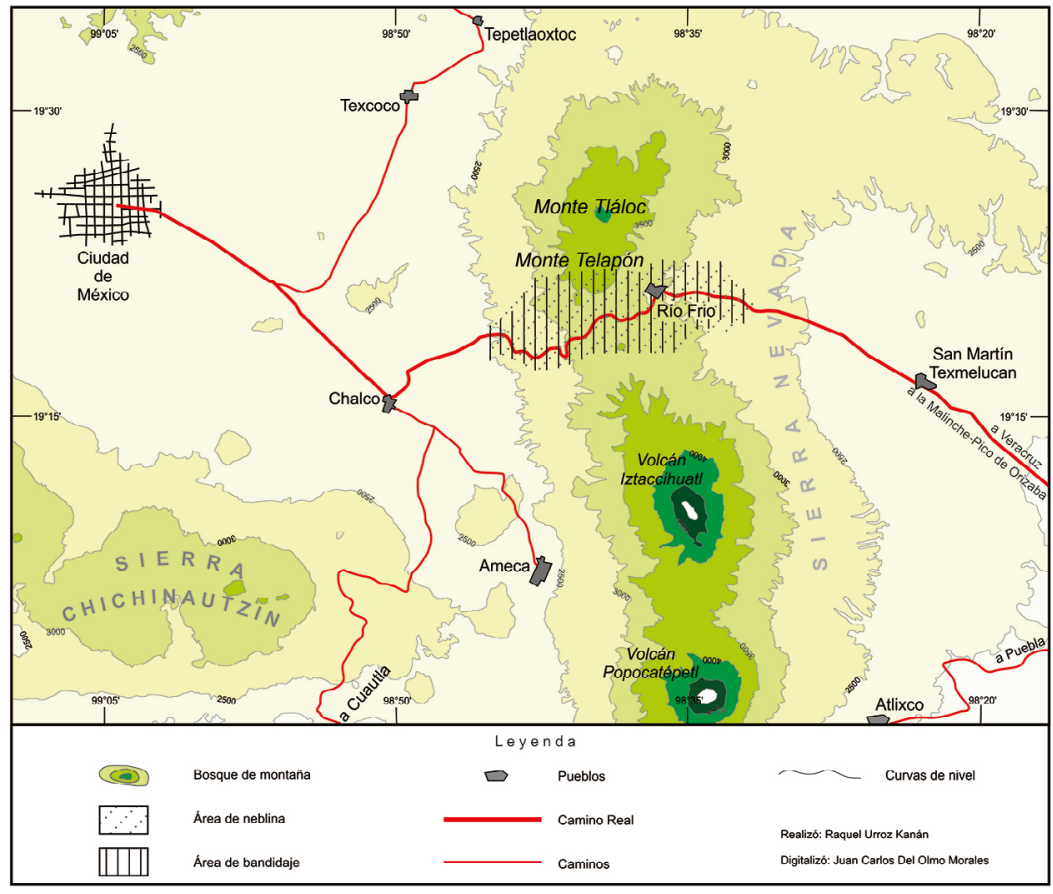

Fuente: Elaboración propia

El otro gran ejemplo en la novela, era"La Ladrillera", el rancho que se ubicaba con rumbo a Tlanepantla, en Cuautitlán, es decir, a "las puertas de la gran capital" (Payno, 2016: 17) (Figura $N^{\circ}$ 1).Sobre él, dice Payno: "El rancho nada tenía que llamase la atención. Los ranchos y los indios todos se parecen" (2016: 15). En él, se producía tlachique, cebada, frijol, nabo, trigo, leche, maíz, chile, tomate, carne y pan (Payno, 2016: 17). ${ }^{21}$ No obstante, llegaba el día en que la tropa de infantería la asaltaba y se apoderaba de sus instalaciones, ${ }^{22}$ al tiempoque el ejército, la declarabaen posesión:precisamente cuando la sala se convertía en el cuartel general. No satisfecho con haber dormido y comido lo suficiente, el cabo Francodecide reclutar a los mejores peones del lugar para el servicio obligatorio y, así, formar el batallón que marcharía rumbo a Guadalajara, donde era urgente apagar la conspiración (Payno, 2016:855).

\footnotetext{
Don Espiridión y Doña Pascuala eran los dueños agricultores de La Ladrillera: "una casa de adobe, mal pintada de cal, compuesta de una sala, comedor, dos recámaras y un cuarto de raya. La "cocina de humo" quedaba en el corral, y contaba con dos metates, comedor, pozo, gallos y gallinas y vacas; además, dos caballos, seis yeguas, dos mulas y seis borregos; así como un círculo donde se trillaba la cebada y se desgranaba el maíz (Payno, 2016: 15-16). En este rancho - el cual, funciona como simbolo y metáfora para el resto-, por tanto, había caballerizas, milpas, peones, yuntas de bueyes y se podía preparar morcilla, chicharrón y quesos que se vendían en la capital (Payno, 2016: 845).

22 Haciendas y ranchos, por igual, se vieron afectados por las operaciones militares y el bandidaje que comprendían saqueos y asaltos, pero también reclutamientos para conseguir mano de obra en la fila de las tropas (Nickel, 1988: 94).
} 
La novela transcurre en una época donde crece exponencialmente el grupo de los jornaleros y arrimados ${ }^{23}$, quienes, por medio del trueque y el trabajo como "acasillados" dentro delas haciendas, se convertían en el gran sector "ambulante" de la población, que de forma estacional o definitiva, ofrecían su servicio enlas haciendas y los ranchos. Esto, a raíz de haber presenciado el desmoronamiento de las cabeceras de los pueblos, y de toda personalidad jurídica que acostumbraban tener su habitantes (Van Young, 2010; Carmagnani, 2011:169; Miño, 2012).

Así lo narra Payno en Los bandidos para el caso de Texcoco y, en especial, para el poblado tan afamado de Tepetlaoxtoc.Allí, los planes del capitán de los bandidos de Río Frío, Evaristo, eranlos siguientes: "con la mayor parte de sus rurales, asisitiese a la feria de Tepetlaoxtoc y reclutase allí cuanta gente creyese necesaria para formar dos o tres cuadrillas; que podian servir alternativamente de soldados o de caballeros errantes, que recorrían el país según conviniera" (Payno, 2016: 1222). Así describe Payno la situación del lugar:

"Vinieron más adelante a establecerse en lo que fue reino de Texcoco los inmediatos descendientes de los conquistadores, y formando lo que, según su importancia y extensión territorial se conoce hoy con el nombre de haciendas y ranchos, y sin necesidad de citas de autores ni de comprobación, debe reconocerse con sólo el hecho de que estos valiosos establecimientos rurales no han podido formarse sino a costa de los primitivos propietarios y sus sucesores hasta época de la Conquista; así, los vecinos nobles que quedaron en Tepetlaoxtoc fueron perdiendo día a día sus terrenos y, pobres y despachados, emigraron a otra parte o murieron, quedando los macehuales y uno que otro de la nobleza azteca que, por una rara excepción, conservaron sus antiguos posesiones" (2016: 1224).

Mientras los pueblos de indios tenían que reclamar tierras usurpadas, otros debían probar posesión de tierras heredadas del pasado. Sin embargo, en el tránsito hacia el liberalismo y hacia la configuración de los nuevos derechos y usos del suelo, ${ }^{24}$ se traficaba o litigaba con las tierras, dando como resultado la apropiación y concentración ilegal. En Los bandidos, el caso de las supuestas tierras de Moctezuma III y del licenciado Lamparilla, resulta clave dentro de la narrativa, porque funge como el abogado que pelea los intereses y los bienes usurpados del heredero del emperador azteca. Lamparilla debía obtener la posesión de todo el pueblo de Ameca y, para su éxito, todo dependía del momento político que fuera "enteramente favorable a los reclamantes de España", para, así, poder defender la Real Cédula de los herederos (Payno, 2016: 975).

En suma, las haciendas, y otras unidades menores, tal y como lo eran los ranchos representan epicentros predominantes para la vida de los personajes en la novela.Dichos lugares absorbían y se apropiaban de las cabeceras y pueblos de indios, corporación, ésta, que perdía entonces toda

23 Los "arrimados", en este contexto, hace referencia a la población compuesta por errantes y desocupados que se volvían, en el mejor de los casos, "trabajadores marginales" de las haciendas, y quienes dejaban de pertenecer a los pueblos tradicionales (Brading, 1995: 104; Castro, 2015: 84-85). Payno explica esta situación así: "El gobierno no ha pensado en establecer casas de asilo ni para el día ni para la noche; pero en cambio en los barrios de México todas las casas de los pobres son casas de asilo para los que son más pobres que ellos" (Payno, 2016: 115).

24 Las comunidades locales y sus territorios buscaban defender antiguos derechos porque eran fuente de legitimidad desde la época colonial (Annino, 2010: 461). Sin embargo, era el tránsito hacia la desamortización o comercialización de terrenos comunales, donde los vecinos pudientes tomaban las tierras arrendadas para hacer propiedad privada; mientras que hacendados, rancheros o especuladores, ganaban en la operación (Escobar, et al, 2017). 
"personalidad" o "espíritu" espacial, para desvanecerse en el paisaje rural, junto con sus antiguos pobladores, quienes se dispersaban y se perdían en él.

\section{Las montañas}

Las montañas que rodean la Cuenca de México fueron un elemento espacial decisivo para el autor de Los bandidos, ya que permitieron la acción de algunas historias centrales en la novela, pero, también, por el hecho de conformar lugares que se recubren de sentido a escala nacional. Siguiendo a Tuan (2018: 121-122), al otorgarles un nombre, como primer paso; y, luego, por medio de los desplazamientos y acciones de los personajes, los lugares se vuelven tema y forma y, en este sentido, las montañas resultan ser epicentros fundamentales en la novela.

Encuadrando a la ciudad del lado sur y este, la Sierra Nevada es una cordillera que corre a lo largo del paralelo 19 grados norte y forma parte del eje neo volcánico. ${ }^{25}$ En ella, se encuentran alineadas algunas de las cumbres más altas de México -arriba de los cinco mil metros-, las cuales emergen y se dejan ver a lo largo del camino real que iba de México a Puebla, y, de allí, hasta la costa de Veracruz. Particularmente, toman relevancia y personalidad en la novela, el complejo montañoso en torno a la localidad de Río Frío, pero también, los volcanes que se encuentran en rededor, como son, el Popocatépetl y el Telapón, entre otros(Figura $N^{\circ} 2$ ).

Sobre todo, es el "monte de Río Frío"que adquiere significación para la trama de la novela, incluso desde la percepción del gobierno que asegura entender los problemas nacionales a partir de un sistema criminal que se desarrollaba hacia este "rumbo". Se creía que los salteadores de caminos eran los responsables de la obstaculización del progreso porque amenazaban el orden social. En la novela, y en palabras del propio gobierno: "el ratero primero, así son todos, después robos mayores en las casas, y al fin el camino real, Río Frío, ésa es su vida; el monte de Río Frío lo tienen como su propia casa" (Payno, 2016: 162). Así, pues, la asociación entre la montaña y los bandidos es una constante espacial en la narrativa de Los bandidos; la misma que resulta imposible desligar porque "aunque el escuadrón de soldados federales explorara y registrara veredas, barrancas y cuevas, el indio y la montaña son uno mismo" (Payno, 2016: 811).

En efecto, cuando Payno pasa revista de costumbres nacionales, se refiere "a la clase que antiguamente llamaban "macehual" o "raza indígena", y a su "miserable vida". ${ }^{26}$ Describe a las "cuadrillas" y "tribus errantes" que se forman y "ganan la parte montañosa y boscosa del país y se establecen en el lugar más escondido que juzgan favorable para satisfacer las poquísimas necesidades de su vida". Ahí, construyen "jacales o chozas de ramas y zacatón", y hacen un "pueblo improvisado" para que al poco tiempo éste sea abandonado y puedan regresar a la hacienda, "donde les dan trabajo y los abrigan durante cuatro o seis meses" (2016: 578-579).

En este contexto rural de descomposición campesina, ya no proliferaban los insurgentes, está vez, el reclamo venía de los bandidos quienes, además de ser indios empobrecidos, en muchos

\footnotetext{
Es una cadena de volcanes que atraviesa el país y la capital de este a oeste, sobre el paralelo $19^{\circ}$

6 De raíz nahua, macehual significa gente común; mientras que en este contexto decimonónico, Payno lo utiliza para referirse a la "raza india", la cual, a su parecer, se caracterizaba por ser "callados, sobrios, humildes, resignados con su suerte, son al mismo tiempo muy hábiles y prácticos en todas las operaciones para la siembra del maíz" (2016: 577)
} 
casos eran soldados que buscaban ahora botín o nombramientos en un medio precario de instituciones y leyes. ${ }^{27}$ En suma, en el escenario del México central plasmado en Los bandidos, no había en absoluto una integración que atravesara clases ni regiones. Sin embrago, en el imaginario nacional, y en su dimensión espacial, el bandidaje era aplicable a una unidad territorial, y esa era la montaña, la misma que "florece en aquellos intersticios geopolíticos sobre los que el control y la influencia del centro tienen poco dominio y donde su influencia judicial es más débil" (Vanderwood, 1994: 130).

Ahora bien, a lo largo de la novela, y particularmente hacia el "rumbo" de Chalco (Figura No 2), se determina la vida de gran parte de los personajes, y estos, a su vez, imprimen su carácter peculiar al lugar. Así lo describe Payno:

Durante la dominación española se le llamaba la provincia de Chalco, y la República le dio el título de ciudad. Sea por la inmediación a las lagunas, sea por la disposición de las montañas o por cualquier otra causa que los observatorios meteorológicos no indagarán jamás, es muy airoso, y sólo le gana en esto, en la tristeza habitual y en el polvo, Tenango del Aire; pero los jueves de cada semana cambia un poco el aspecto con la feria de maíz. Allí van los hacendados pobres y que sin embrago quieren arrastrar a toda costa coche en México, no solo a vender el grano, sino la cosecha en berza; allí van los administradores ladrones a jugar onzas de oro como testimonio de la buena dirección de las fincas de campo se sus amos; allí van los jugadores ambulantes de ruleta y baraja, y allí van también no pocos ladrones a ver lo que se pescan y a indagar quién tiene dinero y quién no tiene, quién viaja o se queda en su casa, para salirle al encuentro y asaltarlo. Además de la plaza y calle Real, que es lo más animado, hay en las orillas cercanas al canal cierto movimiento diario con la entrada y salida de las trajineras y con la llegada de los arrieros de la Tierra Caliente (2016: 509).

En Chalco, en efecto, abundan "hacendados pobres" (Payno, 2016: 508): presa fácil para ser robados o volverse víctimas de caciques que enajenaban el área. Es el caso de Los Melquiades, quienes habían usurpado las tierras de Ameca, precisamente a las faldas de los grandes volcanes. Chalco es una ciudad en el Estado de México que abre sus puertas naturales con dirección sur, hacia una vía geográfica que conduce a los estados de Morelos y de Puebla (Figura $\mathrm{N}^{\circ} 2$ ). Es precisamente uno de los "rumbos" que describe Payno con mayor ahínco: de tal fertilidad por sus reservorios de agua que descienden de las montañas, que forma un valle ancestralmente propicio para la agricultura: En efecto, México recibía granos, semillas, flores y frutas de las haciendas situadas en los márgenes del lago de Texcoco: "los azúcares y frutos de la Tierra Caliente que conducen los arrieros hasta Chalco, que es, como dicen, la "boca" de la Tierra Caliente, o más bien una especie de puerto de depósito, del carbón, leña y madera que se labra en las montañas" (2016: 347).

\footnotetext{
En esta línea, ya se ha escrito mucho sobre el bandidaje como un acto no incorporado ni penalizado aún por las leyes; también se ha reflexionado en torno de la figura del bandido y su ambigüedad como idea, sobre todo, en el sentido de los vínculos con el gobierno. En suma, el bandidaje representaba una respuesta frente a la crisis, una lucha entre la clase expulsada del campo, y la burguesía naciente; un fenómeno de resistencia y de conciencia de identidad, ya no política o nacional, sino del mundo marginal y periférico donde los espacios, la población y los recursos, no se definen aún, ni se controlan, ni se limitan. Por el contrario, los gobiernos nacionales reconocen que el bandidaje subraya sus debilidades y por tanto mina su legitimidad (Pacheco, 1985; Vanderwood, 1994; Davobe, 2007).
} 
Amecameca -o Ameca en la novela- sigue estando sobre el eje volcánico, y al sureste de la capital; es una población naturalmente rica porque se abastece de agua directamente del deshielo tanto del Iztaccíhuatl, como del Popocatépet(Figura $N^{\circ} 2$ ). Y aunque este complejo volcánico de más de cinco mil metros de altura forma parte del paisaje cultural de poblaciones que lo rodean en los estados de México, Morelos y Puebla, en Los bandidos, es el poblado de Ameca y el Popocatépetl los que componen un binomio cultural ligado por la geografía humana. ${ }^{28}$ Así lo percibeel Licenciado Lamparilla, quien busca defender los intereses de su cliente y expresa: "Creo que antes de dos meses estaré en posesión de los antiguos dominios y patrimonio de Moctezuma III y de muchas haciendas y de todo ese volcán que vemos desde aquí, si no es que también entra en el negocio el Iztaccíhuatl (Payno, 2016: 349).

En este mismo rumbo y eje montañoso, se levanta El Telapón, volcán de más de cuatro mil metros de altura en el Estado de México, precisamente entre Chalco y Texcoco. En este monte lleno de bosque, liebres, venados y culebras, se entreveran ranchos improvisados para funcionar como "madriguera" de los ladrones (Payno, 2016: 560). Así, describePayno estos espacios: "situadas en una meseta de la montaña, estaban rodeadas de un bosque tan espeso y frondoso que ha sidojefe de los asaltantes enmascarados (2016: 561). En efecto, Evaristo era un prófugo que venía huyendo de la capital, y "su pensamiento favorito era marcharse a Río Frío, refugio tradicional y seguro de los bandidos y proscritos" (Payno, 2016: 356). Esto ya se sabía por parte del gobierno federal, y a los bandidos se les perseguía por el rumbo de Chalco o por Puebla, pero con poco éxito cuando se refugiaban en Ameca para, de allí, introducirse en el bosque de Río Frío: "tan espeso y lleno de barrancas, que el que lo conoce y se esconde allí, no lo puede sacar ni toda la policía junta" (Payno, 2016: 494). Precisamente en esto consittían los planes de Evaristo quien -junto con Hilario, ladrón y socio-, buscaban convertirse en "dueños y señores de la montaña" (Payno, 2016: 609); y sólo, así, alcanzar "el monopolio del robo" del camino real que iba hacia Puebla o, bien, regresaba de Veracruz hacia la capital,vía Río Frío. ${ }^{29}$

Todo comenzó cuando Evaristo exploró la montaña junto con sus barrancas, luego, se familiarizó incluso con los árboles, y aprendió a reconocer las corrientes de agua, las cuevas y las vertientes que descendían hacia Texcoco y Ayotla (Figura ํ2).Evaristo, en suma, venció a la naturaleza y el asecho de sus bestias; fundó, luego, su ranchito - Los Coyotes-, después de haber examinado "caminos, ranchos, pueblos, mesones, fincas y veredas de ganado que se prolongaban hasta Tulancingo y Chalma" (Payno, 2016: 605).

Al norte de la Sierra Nevada, precisamente donde se levanta el volcán Telapón y hacia los límites con el estado de Puebla, se debía cruzar el paso de Río Frío, una localidad en Ixtapaluca, estado de México. Sin embrago, en Los bandidos, Río Frío es más que eso: es un paso de montaña en la misma línea de cumbres, y entre el Iztaccíhuatl y el Monte Tláloc; es monte; era bosque de

\footnotetext{
Así lo entiende el licenciado Lamparilla en la novela, quien busca defender las tierras fértiles del área tomadas ilegalmente por los Melquiades. El negocio es defender, frente al Ayuntamiento, las posesiones de su cliente y único heredero: Moctezuma III. Eran antiguos dominios de su linaje los que incluían, "además de ocho haciendas en esta jurisdicción y cuyos nombres constan en la misma Real Cédula" (Payno, 2016: 452), más "todo el volcán Popocatépetl con sus bosques, aguas, barrancos, arenas, nieves, azufre y fuego interior" (Payno, 2016: 504).

29 El constante asalto a las diligencias se repetía en el tramo que iba de Chalco a Perote, y esto por causa de la "poca coordinación que retiró soldados federales en el camino y el gobierno de Puebla que retiró sus fuerzas" (Payno, 2016: 744). En cambio, el tramo que iba de Xalapa a Veracruz era seguro (Payno, 2016: 750).
} 
pinos, encinos y de cedros talados por los carboneros; era refugio para bandidos, y era el "cuartel general" fortalecido por Evaristo.

Este criminal -haciéndose pasar por "valentón y honrado" hombre de tierras, y que además se hizo nombrar "capitán de rurales"-, pretendía en el fondo "ligar" la vereda, desde donde se encuentran las chozas de los indios carboneros (Payno, 2016: 823), con su propia guarida. Luego, la conexión llegaría hasta el albergue de Río Frío, precisamente donde paraban las diligencias a las horas del almuerzo y en donde se podía asaltar a los viajeros que hacían su camino a la costa (Payno, 2016: 588-589). Para esta misión, Evaristo reclutaba a "vagos y viciosos"; peones e indios garroteros de Texcoco, Chalco y Tepetlaoxtoc; incluso, podía ser parte de sus cuadrillas, los "rancheros sin colocación" del Estado de México. Por esto, los bandidos, se refugiaban en el bosque, donde los toros y vacas han marcado las veredas; $y$ los indios y peones, los senderos que bajan a Texcoco, particularmente a Tepetlaoxtoc, donde se obtenía caballos, burros, fusiles e instrumentos de labranza (Payno, 2016:580).

En suma, lugares como Río Frío, Tepetlaoxtoc y Texcoco, se habían vuelto sitios donde sólo los empobrecidos podían pensar en reforzarse con "caballos, machetes y pistolas" para, luego, entregarse al ambulantaje en manos de capitanes, hacendados o cabezas del bandidaje en donde, el mejor lugar resultaban ser las montañas que los circundaban. Río Frío, entonces, formaba parte de un paisaje más extenso, el de un sistema montañoso de picos, en la misma línea que llegaba hasta el volcán La Malinche y, luego, al Pico de Orizaba, en Veracruz. ${ }^{30} E n$ conjunto, esto lugares altos y boscosos, eran precisamente los que no podían ser custodiados ni controlados por el gobierno federal, es decir, el poder político no lograba una integración espacial, lo que, en cambio, hacíala cultura popular, es decir, la clase desposeída encontrabaespacios reducidos y diversos intersticios donde poder establecersey subsistir.

\section{Los caminos}

La antes denominada "América del norte española", había sido un área de expansión constante y de crecimiento de núcleos de población, los cuales se articulaban a partir de centros mineros y agrícolas establecidos desde el XVI. No obstante, esta área quedaba orientada hacia la ciudad de México donde, precisamente se acuñaba la plata recogida (Del Río, 2009). ${ }^{31}$ Estas grandes unidades de producción se encontraban cerca del camino real o, en su defecto, a lo largo de los principales ramales que se conectaban con lo que resultaba ser la columna vertebral. Se trataba del camino de tierradentro,el cual vinculaba la capital con todo el norte del país de tal modo que, las relaciones longitudinales con respecto al centro, eran predominantes, así como la economía y la política del septentrión mexicano seguía estando ligada a la capital (García, 2014b: 376).32

\footnotetext{
30 El también llamado Citlaltépetl, es un volcán ubicado en los límites de Puebla y Veracruz, pero perteneciente, ya, a la Sierra Madre Oriental. Sobre el Pico de Orizaba, Payno dejó testimonio de su "impresión sobre la magnificencia de la vista centrada en el volcán más alto de México". Además, Payno hace referencia constante al paisaje de fincas que producían grandes fortunas al tener el monopolio del tabaco, el cuál reprobó y combatió. Sobre todo, el autor de Los bandidos, quiso denunciar la necesidad urgente de abrir el camino de vías férreas hasta el puerto de Veracruz, para el "progreso de la Nación" (Payno, 2007).

31 El Consulado de comerciantes, el cual fungía como prestamista, residía en la capital. También, la Casa de Moneda, donde se acuñaba la plata, se encontraba en la ciudad de México. No obstante, la descentralización comenzaba a desarrollarse, por ejemplo, en el estado de Chihuahua, ya había una jurisdicción estatal, que era Parral, por donde debían pasar los mineros o las diputaciones de minas (Cramaussel, 2016: 139).

32 De hecho, las intendencias del siglo XVIII tuvieron el propósito administrativo de integrar espacialmente un norte poco poblado, lejano y marginado (García, 2014b: 381).
} 
Todas las redes viales, entonces, tenían como eje principal este camino real, el cual conectaba la capital, hasta llegar a Santa Fe, en Nuevo México (FiguraNº1). ${ }^{33}$ Un primer tramo,iba de la ciudad de Méxicohasta Querétaro, y éste se había abierto desde épocas coloniales para otorgar tierras como mercedes reales. Sin embargo, entre estos dos destinos, habían puntos intermedios que eran Tlanepantla, Ecatepec y Cuautitlán, y cuyo paisaje cultural estaba poblado por ranchos y haciendas,tal y como lo era, La Ladrillera enLos bandidos. ${ }^{34}$ En el Bajío, ${ }^{35}$ de hecho, los soldados federales hacen servicios en Querétaro y Guanajuato,porque desde allí, era posible movilizarse a cualquier punto del país para perseguir a los que "buscan desestabilizar a la patria con sus movimientos emancipatorios" (Payno, 2016: 820).A partir de aquí, el camino podía encontrarse muy poblado y transitado por empresas colectivas, las cuales se movían sobre recuas de mulas paracruzar el Bajío y llegar, ya fuera a Zacatecas, a Chihuahua o a Nuevo México. Sobre todo, era un flujo constante de mercaderes, quienes llevaban sus productos a las fiestas de culto y a las ferias que se desarrollaban cada año en varios puntos del camino que llegabanhasta Taos en Nuevo México (Figura No1). ${ }^{36}$

En Los bandidos, el gran destino norteño para sus personajes, era, sin duda,la feria de San Juan de los Lagos, en Jalisco, a la cual, se llegaba por tierradentro una vez atravesado los estados de Guanajuato y de León, aunque también se podíaentroncar por el camino alterno de Guadalajara(Figura $\mathrm{N}^{\circ} 1$ ). Payno describe, así, tal movilidad:

El camino real de la ciudad de México al interior, muy transitado en todo el año, en los meses de noviembre y diciembre no podía bastar a tanta gente de a pie; a tantas recuas de mulas cargadas de cuantas mercancías son imaginables; a tantos coches bombés, es decir, en forma de globos, tirados por ocho o diez mulas; a tantas partidas de rancheros y de mujeres caminando en bandadas, cantando, riendo, comiendo y durmiendo la siesta en las orillas del camino; una aglomeración, en fin como quien dice, "del mundo entero", que salía de su casa y se encaminaba a la feria de San Juan de los Lagos (2016: 1266).

Aunque el destino final, para toda la gente habitante de la misma nación, era San Juan de los Lagos, y quienes tenían el propósito de presenciar y vivir la feria que se llevaba a cabo cada invierno, el camino en sí mismo, parecía fuese una antelación concreta de aquel lugar lúdico y simbólico. No obstante, Payno se pregunta la razón por la cual, se elegía para tal función, precisamente un sitio tan inhóspito, con tan poca infraestructura y tan lejano de la capital, el cual adquiría de todos modos tal relevancia y sentido cultural para sus visitadores. Así se lo cuestiona el autor, en una de sus digresiones dentro de la novela:

\footnotetext{
33 Es cierto que existían algunos enlaces transversales entre regiones del norte, por donde circulaba la palta, productos agropecuarios y artesanales. Sin embrago, la razón geográfica del vínculo principal con la capital del país, era que, para los comerciantes, arrieros, las caravanas integradas por recuas, hatajos o carros de bueyes, o para las carretas tiradas por mulas, era más fácil conectar los caminos por el interior, que por las sierras o las costas de las vertientes (De Río, 2009: 73-74).

34 En realidad, desde Querétaro y Guanajuato, se abrían muchos ramales hacia Michoacán o Guadalajara. Y otro camino más, podía ser el costero, el cual conectaba a Guadalajara después de haber cruzado el río Lerma. De alli, se llegaba a Tepic, cruzaba Sinaloa y el río Yaqui, a la altura de lo que hoy es Tucson, en el desierto de Arizona (Cramaussel, 2016: 138) (Figura №1).

35 Región centro norte-occidente del país, que se ubica al norte del río Lerma, y que comprende parte de los estados de Aguascalientes, Jalisco, Guanajuato, Michoacán y Querétaro.

36 Payno fue testigo de las carabanas de contrabando, las cuales entraban por los puertos de Mazatlán, de Matamoros y de Guaymas, con el fin de proveer de sus productos a Chihuahua, Durango, Nuevo México, Coahuila, Nuevo León y a la feria de San Juan de los Lagos. Lo que resultaba más barato que lo que entraba por Tampico o Veracruz (1999: 133) (Figura Nº1).
} 
Las peregrinaciones de Querétaro a Celaya, ni la de Teptlaoxtoc, se comparaban con Lagos, en diciembre. Lagos, camino a Guadalajara, es una villa situada en un terreno pedregoso y árido. Pero ¿porqué se eligió para esta cita anual de todo el comercio de la república un pequeño, triste, árido, con pocas casas para tanta concurrencia, sin paseos, sin teatros, sin portalerías, sin nada que lo pudiera hacer cómodo y agradable, y sin más atractivo religioso que un pequeño santuario en un cerro, y cuya Virgen no tiene, como otras, tanta fama de ser milagrosa? (2016: 1256).

En Lagos, se llevaba a cabo tal festín de carácter religioso y comercial, y que podía concentrar tal carga cultural que, en palabras de Payno, "suplía con una ciudad improvisada" y en donde se montaba, incluso, una plaza de gallos, un teatro, unsalón de títeres, cafés, fondas y hoteles, aunque "todo de lo más frágil, de lo más ligero" (2016:1260).Y continúa describiendo su construcción temporal y material:

Después de la ciudad de piedra, seguía la de madera y después los campamentos. Los cincuenta o sesenta carros de Chihuahua, con sus muladas, ocupaban un espacio inmenso en el declive de la loma.Carros de Coahuila y Texas, formaban un semicírculo de hatos de las diversas recuas de arrieros, que conducían de todas partes del país vinos, aguardientes, ropa, semillas y cuanto Dios creó. Se establecían las pastorías de carneros de las haciendas de Coahuila, Chihuahua, y Nuevo México. Los caballos de Guanamé, del Sauz, de Tamaulipas, de Coahuila y de otros puntos. Los cerdos y burros, también en corrales, cerraban este inmenso círculo que, como hemos dicho, hacía horizonte y se perdía de vista entre los pliegues del terreno. El paisaje en conjunto presentaba un aspecto grandioso y de una novedad que atraía a multitud de personas ricas del interior que, sin tener negocios ni comercio, se pasaban ocho o quince días no sólo contentos, sino casi locos, viviendo en sus coches, que eran salones de recibir y comedores durante el día,y recámaras muy abrigadas en la noche (2016: 1256-1263).

Además, el significado cultural de Lagos quedaba expresado en su carácter comercial. Es decir, los productos que se vendían y se compraban en la feria, representaban asimismo, sus propios lugares de procedencia. En ese sentido, Payno no escatima endescribir y ordenar los objetos que se podían encontrar en la feria, junto con sus lugares deorigen. Así, lo narra:

De París, dijes y joyería, de Burdeos y Havre, llegan embarcaciones por Veracruz con mercería fina, lencería inglesa y alemana, el cristal y loza que entraba por San Blas y Mazatlán, de Chihuahua venían carros llenos de algodón, barras de cueros, plata, cobre y oro, de Nuevo México pastorías de esos carneros de fino y espeso, de Texas, carros cargados de lienzos de algodón ordinarios, de loza corriente y de ferretería e instrumentos de labranza. Mercancías procedentes del Mar del Sur, pañuelos y pañolones de seda de brillantes colores, la variedad de indianas, las frescas y blancas piezas de lino de Irlanda, las docenas de medias de hilo de Escocia. Pues únicamente en San Juan era donde cada año se encontraba esos maravillosos chales de China que eran la delicia y usaban las ricas y principales señoras de Guadalajara, de México y de Veracruz. Azúcares de Veracruz, Cuautla, Cuernavaca y Matamoros, y piloncillo de Linares y Monterrey y, además, cacao de Tabasco y Soconusco, vainilla de la costa del Golfo, cañas de azúcar, dátiles, plátano pasado, quesos de higo y de tuna, palanquetas de nuez de Pachuca, cuero de membrillo, tamarindo de 
Pátzcuaro. Pieles curtidas de tigre y de pantera; grandes cueros de cíbolo y de gamuza, industrias casi únicas de los indios salvajes de las praderías fronterizas. Sillas de montar, aparejos, atarrias bordadas y fustes de Querétaro (2016:1270-1271).

En efecto, Lagos y el camino de tierradentro que llevaba a él, configuraron, más que un camino o un sitio, una estructura en la narrativa espacial de la novela, en el mismo sentido en que Tuan lo señala, es decir, como epicentros fundamentales. Esto es, existen ciertos lugares con contenido cultural, cuyo simbolismo permite imprimir en ellos, un carácter y un poder, los cuales se volvían realidades espaciales con profunda identidad a cualquier escala (2018: 121-122). En suma, el camino de tierradentro, junto con su destino final, que era la feria de San Juan de los Lagos, fue el vehículo espacialque permitía el gran encuentro social, donde no sólo se dabanlas transacciones económicas, sino donde el nacionalismo se materializaba. Es decir, Lagos era el lugar donde se expresaba un sentimiento que todos compartían, y no sólo de dicha que proporcionael entretenimiento, sino la integración del espacio nacional en toda su dimensión cultural.

\section{Conclusión}

El siglo XIX vivía nuevos acomodos en materia espacial relacionados con el ideario físico e ideológico del estado-nación, así como con las estructuras sociales, tanto rurales como urbanas, las cuales daban lugar, a nuevos patrones económicos que se establecían después de la guerra de independencia. Parte del sentimiento de pertenencia y de conciencia nacional, era la visión geográfica de la nación, la cual formó parte del ambiente periodístico que buscaba abonar al proyecto liberal. Por medio de la literatura, en sus diferentes expresiones, escritos como los de Manuel Payno, contribuyeron a configurar el paisaje cultural de la nación. En efecto, la novela decimonónica y, en especial,Los bandidos, presenta un repertorio de lugares que, en su carácter de epicentros, reúnen un "conjunto de cualidades" que van más allá de la mera ubicación (2018: 84), y que brindan una "visión del mundo" que se organiza a través de la sensación, la percepción y cierta conceptualización del espacio (2018: 57-58)Tal y como Payno buscó descubrir, retratar ytransmitir el nuevo diseño de territorio que tocaba enfrentar a los nuevos ciudadanos que formaban la nación mexicana.

De esta forma, precisamente, la geografía humana deja de ser abstracta y se vuelve susceptible de ser construida con el lenguaje y el poder "metafísico" de la literatura (Tuan, 2018: 112-113). Esto es, a través de los símbolos, los rumbos, las relaciones y las costumbres que la narrativa literaria permite expresar. Así,el "discurso del lugar" crea "mundos fundacionales"una vez que alcanzan la conciencia pública y se fijan con permanencia y estabilidad entre sus usuarios,por medio de fuertes lazos afectivos (Tuan, 2018: 120). Los mundos de ficción, entonces, contaminan el mundo real, permitiendo que la simple imaginación literaria transforme los lugares de la vida pública y cotidiana en sitios de la cultura nacional.

Este fue el contexto cultural del México decimonónico, el cual permitió que una pluma como la de Payno,desarrollara la posibilidadde construir lugares apegados a la tradición por medio del discurso literario; sitios que no solo eran reconocibles para el lector -por evidenciar la realidad espacial vivida- y que, además, se confundían con ella. Este trabajo narrativo sucedíaa raíz de las experiencias y observaciones que hizo Payno en sus recorridos y viajes por el territorio de Mé- 
xico, los cuales cobraban relevancia a través de su obra literaria, y en especial, en Los Bandidos. Esta era la grannovela que contribuyó a crear la imagen del país conformado por su capital y sus montañas circundantes, por el campo y sus paisajes, así como por las fronteras septentrionales siempre amenazadas.

De modo que, si pudiéramos organizar los elementos del sistema que tuvo en mente Payno para modelar el territorio nacional, podría pensarse en algunos de carácterestructural, como lo fueron, el mundo rural dominado por las haciendas, las montañas que enlazaba a la capital con los espacios fuera del alcance del dominio federal, y los caminos reales que vinculaban todas las regiones. En especial, es Lagos, junto con su feria, el lugar donde tenía cada año, un encuentro nacional; donde se marcaba el sentimiento colectivo, que era la única posible expresión de unidad y sinónimo de nación en esos momentos; y, por último, el lugar que consolidaba todo un paisaje cultural a escala nacional.

En efecto, la construcción cultural del espacio mexicano en el siglo XIX fue a escala nacional, y esto se llevaba a cabo, por medio de la narrativa que describía y daba vida a los lugares y las regiones concretas del territorio en plena formación.Y aunque el autor de Los Bandidos pensaba en una integración del paisaje mexicano de naturaleza capitalista e industrial; la base de ella, debía fundarse, primero que nada, en las poblaciones y sus vínculos entre ellas, y no a costa de intereses particulares mezquinos o sueños aristócratas. No obstante, y al final de cuentas,el mundo que retrataba Payno, se impone la distopía: tiemposde transición donde imperaba el bandidaje y los saqueos, las usurpaciones de la tierra, los peones acasillados y los militares empobrecidos, en fin, las injusticias y las desigualdades. El diseño que imagina Payno sobre la estructura espacial mexicana, a pesar suyo, no puede articularse: este corre de forma longitudinal del centro al septentrión mexicano y solo da cuenta de la imposibilidad de su aislamiento y a la vez de su posible fragmentación.

\section{Referencias bibliográficas}

ANDERSON, B. Imagined communities. Reflections on the Origin and Spread of Nationalism.London: Verso, 1991.

ANNINO, A.La ruralización de lo político. En: ANNINO, A. (Coord.). La revolución novohispana, 1808-1821. México: Fondo de Cultura Económica, 2010, p. 384-464.

BLANCO, J. Aspectos de la novela popular mexicana en el siglo XIX. En: Suárez, L. (Coord. y Ed.) Tras las huellas de Eugenio Sué. Lectura, circulación y apropiación de Los misterios de París. México: Siglo XIX/Instituto Mora, 2015, p. 256-270.

BRADING, D. El ranchero mexicano: campesinos y pequeños propietarios. En:ÁVILA, R; MARTÍNEZ, C.\&, MEYER, J.(Coords.). Las formas y las políticas del dominio agrario. Homenaje a Fran ois Chevalier. México: Centro de estudios mexicanos y centroamericanos/UNAM/Universidad de Guadalajara, 1995, p. 96-110.

CARMAGNANI, M. El otro Occidente. América Latina desde la invasión europea hasta la globalización. México: Fondo de Cultura Económica- El Colegio de México, 2011. 
CARRERA, M. Traveling from New Spain to Mexico. Mapping practices of nineteenth century Mexico.Duke: Duke University Press, 2011.

CASTRO, F. Los ires y venires del fundo legal de los pueblos de indios. En: MARTÍNEZ, M. (Coord). De la historia económica a la historia social y cultural. Homenaje a Gisela von Wobeser. México: Instituto de Investigaciones Históricas/UNAM, 2015, p. 69-103.

CRAMAUSSEL, Ch. (Ed.). Los caminos transversales. La geografía histórica olvidada de México. México: El Colegio de Michoacán/Universidad Juárez del Estado de Durango, 2016.

DAVOBE, J P. Nightmares of the lettered city. Bandity and literatura in Latin America 1816-1929. Pensilvania: University of Pittsburgh Press, 2007.

DEL RÍO, I. Estudios históricos sobre la formación del norte de México. México: Instituto de Investigaciones Históricas/UNAM, 2009.

DUCLAS, R.Manuel Payno et los bandidos de Río Frío.México: Institut Francais d'Amerique Latine, 1979.

ESCOBAR, A.; Falcón, R.\& Sánchez,M. Introducción. En: ESCOBAR, A.; FALCÓN, R. \& SÁNCHEZ, M.La desamortización civil desde perspectivas plurales. México: El Colegio de México/El Colegio de Michoacán/Centro de Investigaciones y Estudios Superiores en Antropología Social, 2017, p. 11-65.

FERNÁNDEZ, F. El paisaje como historiografía. La geografía cultural ante la lectura del espacio. En URQUIJO, P;VIEYRA, A \& BOCO, G. (Coords.).Geografía e Historia ambiental. México: Centro de Investigaciones en Geografía Ambiental/UNAM, 2017, p. 53-70.

GARCÍA, B. Los poblados de hacienda: personajes olvidados de la historia del México rural. En: GARCÍA, B. Antologías. Tiempos y lugares. Antología de estudios sobre poblamiento, pueblos, ganadería y geografía en México. México: El Colegio de México, 2014a, p. 85-130.

GARCÍA, B.El espacio del (des) encuentro.En: GARCÍA, B. Antologías. Tiempos y lugares. Antología de estudios sobre poblamiento, pueblos, ganadería y geografía en México. México: El Colegio de México, 2014b, p. 365-402.

GLANTZ, M.La novela popular mexicana. En:GLANTZ, M. Ensayos sobre literatura mexicana del siglo XIX. México: Fondo de Cultura Económica, 2010, p. 23-200.

GUERRA, F. X. Modernidad e independencias. Ensayos sobre las revoluciones hispánicas. México: Fondo de Cultura Económica, 2014.

LANGUE, F. Los señores de Zacatecas. Una aristocracia del siglo XVIII novohispano. México: Fondo de Cultura Económica, 1999. 
MIÑO, M. Sistemas de trabajo y trasculturación en Hispanoamérica, 1640-1814. En: PÉREZ, S; MIÑO, M\&AMARO, R. (Coords.) El mundo del trabajo urbano. Trabajadores, cultura y prácticas laborales. México: El Colegio de México, 2012, p. 27-67.

NICKEL, H.Morfología social de la hacienda mexicana. México: Fondo de Cultura Económica, 1988.

MONSIVÁIS, C. Manuel Payno: México, novela de folletín. En: GLANTZ. M. (Coord.) Del Fistol a la Linterna. México: UNAM, 1997, p. 241-254.

PACHECO, J. E. Bandidos de ayer y hoy. En: Proceso, 1985, no. 441, p. 6-16.

PAYNO, M. Obras Completas, Panorama de México. México: CONACULTA, 1999.

PAYNO, M. Obras Completas, Compendio de Historia de México, Historia Nacional. México: CONACULTA, 2002.

PAYNO, M. Obras Completas, Memoria sobre el ferrocarril de México a Veracruz. México: CONACULTA, 2007.

PAYNO, M.Los bandidos de Río Frío, México: Secretaría de Cultura, 2016.

QUIRARTE, V. Elogio de la calle. Biografía literaria de la ciudad de México. 1850-1992. México: Ediciones Cal y Arena, 2016.

RUIZ, Á.El género, la máscara y el mito. En: Actas del XV Congreso, Asociación Internacional de Hispanistas,2007, Vol. IV, p. 645-652.

SCLÖGEL, K.En el espacio leemos el tiempo. Sobre Historia de la civilización y Geopolítica.Madrid: Ediciones Siruela, 2007.

SORIANO, K.En busca de un mapa final: Geografía y prácticas de territorialidad en el siglo XIX mexicano. En:Iberoamericana, Nordic Journal of Latin American and Caribbean Studies.2018, no. 47,p. 13-23.

TUAN, YI-FU. El arte de la geografía. En:NOGUÉ, J.(Ed.). Barcelona: Icaria Editorial, No. 11, 2018.

URROZ, R. La construcción de una geografía cultural en una novela mexicana del siglo XIX: La ciudad de México en Los bandidos de Frío de Manuel Payno. En Boletín del Instituto de Geografía, México: Instituto de Geografía, UNAM, 2019, no. 98. https://doi.org/10.14350/rig.59762

VANDERWOOD, P. Los Bandidos de Manuel Payno. En:Historia Mexicana. 1994, no. 1, p. 107-139.

VAN YOUNG, E.El momento antimoderno: localismo e insurgencia en México, 1810-182. En: ANNINO, A. (Coord.). México: Fondo de Cultura Económica, 2010, p. 221-292. 
